\title{
Musculoskeletal Disorders among Dentists in Northwest area of the state of São Paulo, Brazil
}

\author{
Ana Carolina da Graça Fagundes Freire', Gabriella Barreto Soares², Tânia Adas Saliba Rovida³, Cléa Adas Saliba \\ Garbin $^{4}$, Artênio José Ísper Garbin ${ }^{5}$
}

${ }^{1} \mathrm{PhD}$ student of Preventive and Social Dentistry - Araçatuba School of Dentistry- Paulista State University / Unesp, Jose Bonifácio Street, 1193, Araçatuba,

São Paulo, Brazil

${ }^{2} \mathrm{PhD}$ student of Preventive and Social Dentistry - Araçatuba School of Dentistry- Paulista State University / Unesp, Jose Bonifácio Street, 1193, Araçatuba,

São Paulo, Brazil. E-mail: gabriella.barreto@yahoo.com.br ,Phone: +55(027)981000511

${ }^{3}$ Professor of the Program of Preventive and Social Dentistry - Araçatuba School of Dentistry- Paulista State University / Unesp. Jose Bonifácio Street,

1193, Araçatuba, São Paulo, Brazil

${ }^{4}$ Professor of the Program of Preventive and Social Dentistry - Araçatuba School of Dentistry- Paulista State University / Unesp. Jose Bonifácio Street,

1193, Araçatuba, São Paulo, Brazi

${ }^{5}$ Professor of the Program of Preventive and Social Dentistry - Araçatuba School of Dentistry- Paulista State University / Unesp. Jose Bonifácio Street,

1193, Araçatuba, São Paulo, Brazil

\begin{abstract}
Objective: To determine the prevalence of musculoskeletal disorders in dentists who attend postgraduate courses in various specialties and establish possible relationships with sociodemographic and occupational factors. Methodology: This is a cross-sectional study where 91 professionals responded to validated instruments: "Work-related activities that may contribute to job-related pain and / or injury" and NMQ "Nordic Musculoskeletal Questionnaire", and variables were also collected regarding sociodemographic and occupational characteristics. Results: WMSDs were often reported in the neck, shoulder, lower/upper back, and hand/wrists. Logistic regression analysis revealed that there was a correlation between reports of WMSD in lower back and work related $(O R=13.40)$. Moreover, associations were found between WMSDs and the occupational factors that can contribute to musculoskeletal disorders. Conclusion: There was a high prevalence of musculoskeletal disorders among brazilian dentists, and that the work-related activities contributed to musculoskeletal disorders in dentists.
\end{abstract}

Keywords: Musculoskeletal Pain; Occupational health; Risk factors; Dentistry.

Received for publication: December 29, 2016 Accepted: May 31, 2017

Corresponding Author: Gabriella Barreto Soares 1193, Jose Bonifacio St Araçatuba - SP- Brazil Phone : +55-027-981000511 gabriella.barreto@yahoo.com.br

\section{Introduction}

Musculoskeletal disorders are generally defined as a group of injuries affecting the bones, muscles and tendons of the body, and can occur after a single event or due to an accumulation of traumas related to labor activity ${ }^{1,2}$.

The dentists highlighted by the vulnerability and problems of various natures in the occupational context. Among these, those related to the specific postures during their clinical activity are evident ${ }^{3-5}$. Since dentistry is a profession that demands attention and precision in movements where the professional must constantly interact with tools and 
equipment to assist in the care, it is natural to experience increased muscle tension exacerbated by the number of hours worked ${ }^{1,3,4}$. In this context, the professional end up sharply bending the body or performing rotations of the regions of the neck and spine, and abduction of the shoulder to improve the field of view and obtain easier access to the oral cavity ${ }^{3-9}$.

The static and sometimes clumsy posture combined with repetitive movements and compression of musculoskeletal structures increase the risk for developing injuries among dental professionals, jeopardizing their health and may lead to the removal from the career ${ }^{1,5,9}$.

To help prevent the installation of musculoskeletal injuries and minimize the negative effects, the professionals should orientate themselves about the risks to which they are exposed. Studies shows a high prevalence of lesions, but few have explored and discussed how early musculoskeletal disorders develop in dentists, thus undermining the implementation of preventive methods $^{5,10}$

Most musculoskeletal disorders may be alleviated with appropriate preventive attitudes, especially before chronic damage is installed ${ }^{1,5-9}$. Furthermore, the adopted work postures and their duration are closely related to musculoskeletal disorders and have their variations among the specialties ${ }^{11}$.

Despite the high prevalence of musculoskeletal complaints described, very little is known about these disorders among dental professionals and their associated factors. In this sense, the objective was to study the prevalence of musculoskeletal disorders and their possible relationship to sociodemographic and occupational variables in dentists who attend postgraduate courses and verify their perception in relation to risk factors for development of musculoskeletal disorders.

\section{Materials and Methods}

This is an epidemiological study, following the ethical standards proposed for studies in humans.

The sample consisted of dentists enrolled in postgraduate courses of various specialties (dentistry, endodontic, periodontic, surgery, prosthodontics, implant dentistry, pediatric dentistry and orthodontic) of a medium-sized municipality in the state of São Paulo, Brazil, during 2016. The dental class board advocates that each specialization class is comprised of 12 students $(\mathrm{N}=$ 96). Dentists with physical limitations and pregnant women were excluded from the study.

Data collection was carried out during 4 months in 2016. The data variables related to sociodemographic characteristics, work and health of the dentists were acquired through a structured questionnaire designed specifically for this study. Socio-demographic variables included age, gender and marital status. Health-related variables included: body mass index (BMI), practice of physical exercises, diagnosis of any disease in the last 12 months and the use of pain medications.

To evaluate the musculoskeletal symptoms, the Nordic Questionnaire developed by Kuorinka was used with the goal of standardizing the measuring of the musculoskeletal symptoms. Brazilian version of the Nordic questionnaire was validated and adapted by Barros and Alexandre in 2003 $3^{12}$. This tool consists of a posterior view of a human figure, which is subdivided in 9 anatomical regions: neck, shoulders, upper and lower back, elbows, wrists/hands, hips/thighs, knees and ankles/feet, and questions about the presence of musculoskeletal pain in any of the 9 anatomical areas, inability to perform normal activities and necessity to consult a health professional. The respondent has to signal with an $\mathrm{X}$ an affirmative or negative response (yes or no). A 12-month period prior to the time of the study was considered for the occurrence of musculoskeletal symptoms.

The questionnaire on risk factors at work that may contribute to musculoskeletal disorders (work-related) was also applied to identify how much work activities contribute to the development of musculoskeletal disorders. This tool was originally developed in the United States by Rosecrance et al. In 2009 it was adapted and validated for Brazilian culture by Colucci and Alexandre ${ }^{13}$. This instrument comprises 15 items that evaluate individuals' awareness of job environment factors and their potential contribution to musculoskeletal disorders. The individuals were asked to indicate on a scale from 0 to 10 (with $0=$ nothing, and $10=$ a lot) how much each variable contributed to the development of pain and lesions related to their current work tasks. Responses were classified in a scale of 3 categories, which indicated severity of symptoms in crescent order: the first, from $0-1$, indicated absence of symptoms; the second, from $2-7$, indicated minimal to moderate symptoms; and the last, from 8-10, indicated severe symptoms.

Data were entered into the database and analyzes were performed using the SPSS version 21.0. To check if the pain interferes with the perception of risk factors for musculoskeletal disorders, professionals were divided into two groups, the group of symptomatic subjects (with pain) and the group of asymptomatic subjects (no pain) to be later compared. This diagnosis was made with the aid of the "Nordic Musculoskeletal Questionnaire" (NMQ). The comparison of the means between groups (symptomatic and asymptomatic) was performed using the Mann Whitney test. The logistic regression was used to analyze the relationship between the sociodemographic variables and the presence of pain. Also performed was an association by reason of the Maximum Like hood performed by associating the general questions of the "Nordic Musculoskeletal Questionnaire" (NMQ) (Question A: Over the last 12 months have you had any problems such as pain, tingling or numbness; B Question: In the last 12 months, were you unable to perform normal daily activities; $\mathrm{C}$ question: in the last 12 months have you consulted a health professional because of this condition; D question: Over the past seven days have you had any problems) with the sociodemographic and occupational variables. A statistical significance level of 5\% was considered for all tests.

The study was approved by the Committee on Ethics for Research on Human Beings of the College of Odontology of Araçatuba of the Paulista State University, and performed with the understanding and a written consent of every participant.

\section{Results}

More than half of the dentists were women (63.8\%) with 
average age of 30 years old (SD 6.16) and single (60.6\%). The majority had practiced for an average of 21 years (SD 9.48). A large part of the sample worked in public and private services $(55.3 \%)$, with a workload of more than 8 hours per day $(36.2 \%)$, and $41.5 \%$ reported not taking breaks between appointments. An half of the study subjects had normal BMI (50.0\%), however, there is a considerable part that was overweight (31.9\%). Alarge number of the dentists $(62.8 \%)$ had practiced physical activity for more than 1 year.

The table 2 indicates that $90.4 \%$ of the sample reported pain in the last 12 months. More than a half of the dentists reported neck pain $(58.5 \%)$, lower back $(57.4 \%)$, upper back $(55.3 \%)$, shoulders $(46.8 \%)$, hands/wrist $(44.7 \%)$.

Table 1 - Sociodemographic and Work Characteristics of Dentists. São Paulo, Brazil, in 2016.

\begin{tabular}{|c|c|c|}
\hline Variables & $n$ & $\%$ \\
\hline \multicolumn{3}{|l|}{ Gender } \\
\hline Female & 60 & 63.8 \\
\hline Male & 34 & 36.2 \\
\hline \multicolumn{3}{|l|}{ Age } \\
\hline 20 to 24 years & 12 & 12.8 \\
\hline 25 to 29 years & 34 & 36.1 \\
\hline 30 to 34 years & 22 & 23.4 \\
\hline 35 to 39 years & 14 & 15.0 \\
\hline 40 to 53 years & 9 & 9.7 \\
\hline No information & 3 & 3.2 \\
\hline \multicolumn{3}{|l|}{ Marital status } \\
\hline Married & 37 & 39.4 \\
\hline Single & 57 & 60.6 \\
\hline \multicolumn{3}{|l|}{ BMI } \\
\hline Underweight & 5 & 5.3 \\
\hline Normal weight & 47 & 50.0 \\
\hline Overweight & 30 & 31.9 \\
\hline Obesity & 12 & 12.8 \\
\hline \multicolumn{3}{|l|}{ Workplace } \\
\hline Public & 22 & 23.4 \\
\hline Private & 52 & 55.3 \\
\hline Both & 18 & 19.1 \\
\hline No information & 2 & 2.1 \\
\hline \multicolumn{3}{|l|}{ Work hours / day } \\
\hline 6 hours & 12 & 12,8 \\
\hline 8 hours & 28 & 29.8 \\
\hline$>8$ hours & 34 & 36.2 \\
\hline No information & 20 & 21.2 \\
\hline \multicolumn{3}{|l|}{ Breaks } \\
\hline Yes & 52 & 55.3 \\
\hline No & 39 & 41.5 \\
\hline
\end{tabular}

Table 2 - Distribution of musculoskeletal symptoms (12 months and 7 days), disability and demand for professional healthcare among dentists. São Paulo, Brazil, in 2016.

\begin{tabular}{|c|c|c|c|c|c|c|c|c|}
\hline \multirow[t]{2}{*}{ Body Area } & \multicolumn{2}{|c|}{$\begin{array}{l}\text { Symptoms } \\
\text { in the last } 12 \\
\text { months }\end{array}$} & \multicolumn{2}{|c|}{$\begin{array}{l}\text { Impediment } \\
\text { to perform } \\
\text { normal } \\
\text { activities } \\
\text { bacause of } \\
\text { this problem } \\
\text { over the past } \\
\text { year }\end{array}$} & \multicolumn{2}{|c|}{$\begin{array}{c}\text { Consultation } \\
\text { with a } \\
\text { professional } \\
\text { in the area of } \\
\text { health because } \\
\text { of this condition } \\
\text { in the past } 12 \\
\text { months }\end{array}$} & \multicolumn{2}{|c|}{$\begin{array}{c}\text { Symptoms } \\
\text { in the last } 7 \\
\text { days }\end{array}$} \\
\hline & $\mathrm{n}$ & $\%$ & $\mathrm{n}$ & $\%$ & $\mathrm{n}$ & $\%$ & $n$ & $\%$ \\
\hline Neck & 41.5 & 58.5 & 93.6 & 6.4 & 81.9 & 18.1 & 74.5 & 25.5 \\
\hline Shoulder & 53.2 & 46.8 & 94.7 & 5.3 & 86.2 & 13.8 & 85.1 & 14.9 \\
\hline Upper Back & 44.7 & 55.3 & 95.7 & 4.3 & 81.9 & 18.1 & 80.9 & 19.1 \\
\hline Elbow & 87.2 & 12.8 & 98.9 & 1.1 & 96.8 & 3.2 & 96.8 & 3.2 \\
\hline Wrist/hand & 55.3 & 44.7 & 96.8 & 3.2 & 87.2 & 12.8 & 85.1 & 14.9 \\
\hline Lower back & 42.6 & 57.4 & 89.4 & 10.6 & 78.7 & 21.3 & 80.9 & 19.1 \\
\hline Hip/haunch & 87.2 & 12.8 & 97.9 & 2.1 & 96.8 & 3.2 & 94.7 & 5.3 \\
\hline Knee & 71.3 & 28.7 & 94.7 & 5.3 & 90.4 & 9.6 & 87.2 & 12.8 \\
\hline Ankle/feet & 81.9 & 18.1 & 93.6 & 6.4 & 94.7 & 5.3 & 94.7 & 5.3 \\
\hline
\end{tabular}

The association test was performed by the Maximum Likelihood of the general questions of the "Nordic Musculoskeletal Questionnaire" (NMQ) and the sociodemographic and work related variables. A statistically significant association was only observed for the daily working hours, when it was presented as very prolonged, hence contributing to the onset of musculoskeletal pain, interfering in performing normal daily activities such as housework, work and leisure $(\mathrm{p}=0.015)$ (Table 3).

Table 3 - Association between general questions of the NMQ and daily work day among dentists. São Paulo, Brazil, in 2016.

\begin{tabular}{|c|c|c|c|c|c|c|c|}
\hline \multirow[b]{2}{*}{ NMQ } & \multicolumn{2}{|c|}{6 hours } & \multicolumn{2}{|c|}{$\begin{array}{l}8 \text { hours } \\
8 \text { hours }\end{array}$} & \multicolumn{2}{|c|}{ More than } & \multirow[b]{2}{*}{$\mathrm{p}$-value } \\
\hline & $n$ & $\%$ & $n$ & $\%$ & $n$ & $\%$ & \\
\hline \multicolumn{8}{|l|}{ GA } \\
\hline Yes & 10 & 83.3 & 26 & 92.9 & 32 & 94.1 & $0.546^{* *}$ \\
\hline No & 2 & 16.7 & 2 & 7.1 & 2 & 5.9 & \\
\hline \multicolumn{8}{|l|}{ GB } \\
\hline Yes & 1 & 8.3 & 5 & 17.9 & 15 & 44.1 & $0.015^{\star *}$ \\
\hline No & 11 & 91.7 & 23 & 82.1 & 19 & 55.9 & \\
\hline \multicolumn{8}{|l|}{$\mathrm{GC}$} \\
\hline Yes & 4 & 33.3 & 11 & 39.3 & 22 & 64.7 & 0.062 \\
\hline No & 8 & 66.7 & 17 & 60.7 & 12 & 35.3 & \\
\hline \multicolumn{8}{|l|}{ GD } \\
\hline Yes & 7 & 58.3 & 18 & 64.3 & 20 & 58.8 & $0.891^{* *}$ \\
\hline No & 5 & 41.7 & 10 & 35.7 & 14 & 41.2 & \\
\hline Total & 12 & 100 & 28 & 100 & 34 & 100 & - \\
\hline
\end{tabular}

**MaximumLikelihoodRatio 
The comparison of the symptomatic and asymptomatic groups was performed by the non-parametric Mann-Whitney test and a statistical significance was observed regarding the presence of pain when the dentist finds himself in an uncomfortable working situation, such as working in a very tight location inappropriately furnished $(p=0.005)$ (Table 4$)$. The situations listed in the "Work-related Activities that may Contribute to job-related pain and / or injury" questionnaire that showed greater significance in relation to the pain experience were: performing the same task repeatedly $(p=0.001)$; work fast for short periods $(p=0.026)$; have to handle or hold small objects $(p=0.006)$; intervals or insufficient breaks during the workday $(p=0.003)$, working in uncomfortable positions $(p=0.001)$; working in the same position for long periods ( $\mathrm{p}=$ value 0.001$)$; bending or twisting one`s back uncomfortably $(p=0.001)$; long working hours $(p=0.004)$ (Table 4). Symptomatic professional has a greater awareness of the risk factors for the development of musculoskeletal symptoms.

Table 4 - Comparison between the presence of pain and the 15 job factors that can contribute to musculoskeletal symptoms featured in the "Work-related Activities that may contribute to job-related pain and / or injury". São Paulo, Brazil, in 2016.

\begin{tabular}{|c|c|c|c|}
\hline \multirow[b]{3}{*}{ Instrument regarding job factors that can contribute to musculoskeletal symptoms } & \multicolumn{2}{|c|}{ Symptoms of pain } & \multirow{3}{*}{$\mathrm{p}$-value } \\
\hline & & & \\
\hline & (SD) & (SD) & \\
\hline Work fast for short periods. & $3.74( \pm 3.27)$ & $1.22( \pm 1.92)$ & 0.026 \\
\hline Have to handle or hold small objects. & $3.51( \pm 3.54)$ & $0.78( \pm 2.33)$ & $0.006^{*}$ \\
\hline Working in the same position for long periods. & $6.78( \pm 2.71)$ & $2.67( \pm 3.32)$ & $0.001^{*}$ \\
\hline Bending or twisting of the back uncomfortably. & $6.66( \pm 2.88)$ & $2.67( \pm 2.60)$ & $0.001^{*}$ \\
\hline Working near or at their physical limit. & $6.00( \pm 2.93)$ & $3.44( \pm 4.28)$ & 0.059 \\
\hline Reaching or working above head level or away from the body. & $4.53( \pm 3.56)$ & $2.56( \pm 3.68)$ & 0.119 \\
\hline Workday & $4.91( \pm 3.30)$ & $1.56( \pm 2.19)$ & $0.004^{*}$ \\
\hline Use tools (format, vibration). & $3.04( \pm 3,16)$ & $2.44( \pm 2.92)$ & 0.627 \\
\hline Work without receiving training. & $3.32( \pm 3.59)$ & $2.78( \pm 3.23)$ & 0.893 \\
\hline General & $4.94( \pm 2.23)$ & $2.44( \pm 2.24)$ & $0.005^{*}$ \\
\hline
\end{tabular}

*Mann Whitney test

In the proposed model, individuals with greater awareness of the risk factors were classified with serious problems, and presented a risk of pain in the lower back 13.40 times higher than the asymptomatic subjects (Table 5).

Table 5 - Multivariate Analysis of the relationship of the Regions Lower back and "Work-related activities that may contribute to job-related pain and / or injury" São Paulo, 2016.

\begin{tabular}{|c|c|c|c|}
\hline \multirow[b]{2}{*}{$\begin{array}{l}\text { Instrument regarding job } \\
\text { factors that can contribute to } \\
\text { musculoskeletal symptoms }\end{array}$} & \multicolumn{2}{|c|}{ Symptoms of pain } & \multirow[b]{2}{*}{$\mathrm{p}$-value } \\
\hline & $\begin{array}{l}\text { Yes } \\
\text { (SD) }\end{array}$ & $\begin{array}{l}\text { No } \\
\text { (SD) }\end{array}$ & \\
\hline Perform the same task repeatedly. & $5.0( \pm 3.33)$ & $1.11( \pm 1.83)$ & $0.001^{*}$ \\
\hline Work fast for short periods. & $3.74( \pm 3.27)$ & $1.22( \pm 1.92)$ & 0.026 \\
\hline $\begin{array}{l}\text { Have to handle or hold small } \\
\text { objects. }\end{array}$ & $3.51( \pm 3.54)$ & $0.78( \pm 2.33)$ & $0.006^{*}$ \\
\hline
\end{tabular}

\section{Discussion}

In this study, the majority of respondents were female (63.8\%), but this condition was not a risk factor for the presence of pain. Dentistry has shown a gradual increase in female workers in recent years ${ }^{11,14-18}$. The correlation between gender and pain becomes more evident with each passing year, this factor must be the mechanical overload caused by double shifts to which women are subjected, thus establishing an association between the female gender and musculoskeletal disorders ${ }^{11,15,19}$. Thus the average age in these surveys showed professionals over 35 years of age $\mathrm{e}^{5,9,15,16}$ and in our study, the average age was 30.68 years, this variable also did not appear as a risk factor or statistical association with reports of pain.

Musculoskeletal disorders can be prevented by adopting a healthier lifestyle such as: nutritional care, practice of sports, performing daily stretches and adoption of ergonomic principles ${ }^{20}$. 
Physical exercise on a regular basis causes circulatory and metabolic adaptations beneficial to musculoskeletal structures, helping to maintain the static and dynamic posture, thus reducing the risk of musculoskeletal injuries ${ }^{11,15,20}$. Although most have reported engaging in physical activity $(62.8 \%)$ with frequency and the Body Mass Index (BMI) found was considered normal $(\mathrm{BMI}=25.02)$, these factors did not help in the prevention of musculoskeletal disorders, a plausible reflection would be a late start to a healthier life style coupled with excessive workload and lack of breaks.

Musculoskeletal disorders have increasingly become a matter of concern, research and discussion worldwide. It is fundamental importance to the quality of the professional and personal life of the dentist, knowing its causes, manifestations and ways to prevent and treat these lesions ${ }^{9}$. In this study, the presence of musculoskeletal disorders was observed in $90.4 \%$ of the professionals, and this is a very high prevalence, and similar results were found in other studies $^{14-16,19,21,22}$.

The regions most committed to musculoskeletal disorders were the neck, upper back, shoulders, wrists / hands and lower back, and similar findings were found in studies of dental professionals ${ }^{14-17,19-21}$. The dentist performs flexion and abduction of the shoulder to serve as a support base for the fine and precise movements performed with the hands, so the more overloaded regions by static muscular effort of these professionals are the neck, shoulder and lower back ${ }^{10,15,21}$. The pain is manifested in higher and lower grades in accordance with the daily demands of static overload that each professional undergoes ${ }^{15}$.

The lengthening of the working day ends up requesting more maintenance on the static posture of the body, causing muscle fatigue, thereby the professional ends up adopting compensatory postures, leading to the onset of muscle pain and decreased strength of the upper limbs $s^{9,15,16}$. This fact can be seen in the results of this study in which the painful manifestation presented a statistical significance with the work hours and insufficient interval / breaks during the labor activity.

The daily working hours of most dentists was over 8 hours, and the breaks was reported by just over half of the subjects. The workload can be considered a pre-determining factor for the development of musculoskeletal disorders, but does not act in isolation. Therefore, professionals who work ergonomically, perform pauses between calls, maintain a workload that does not exceed 8 hours / day are less likely to develop musculoskeletal disorders ${ }^{15,20,21}$. One must also be aware of the ergonomics afforded by the furnishings in the workplace, such as tables and chairs, in the case of dentists, whose design often does not meet the biotype of the users, since they are manufactured in a standardized manner, and working on a device to which their body cannot adapt comfortably and ergonomically can affect the performance of the professional at work ${ }^{23}$.

Among the surveyed correlations, situations of discomfort at work get highlighted in this and other studies ${ }^{14-16,21}$, presenting an intimate relation to the painful events. In the analysis of the situations considered uncomfortable, the ones most significant in relation to the pain experience were: performing the same task repeatedly; work fast for short periods; have to handle or hold small objects; working in uncomfortable positions; working in the same position for long periods; bending or twisting of the back uncomfortably. This can be explained by the overloading of the muscles of the upper body (including shoulder, neck, hands) that the dentist does when performing their work activities, coupled with the stress and excessive workload ${ }^{5,16}$.

In the proposed model, individuals classified with severe problems presented greater perception of risk factors for the development of musculoskeletal disorders. Thus, dentists with musculoskeletal disorders have 13:40 times greater risk of developing pain in the lower back than asymptomatic individuals. The lack of stability and alignment of the spine associated to work for an extended time in the same position can generate decreased muscle flexibility and joint mobility, leading to muscle fatigue ${ }^{15,24}$. Professionals who complain of pain first use some form of drug therapy to relieve this sensation, seeking professional help from a specialist only after the persistence of symptoms $s^{15,19,24,25}$.

The pain can cause limitations in performing daily professional activities in individuals with low back pain or other musculoskeletal disorders ${ }^{15}$. When performing the association of general questions of the "Nordic Musculoskeletal Questionnaire" (NMQ) with the sociodemographic and occupational variables, a statistical significance was observed only in the hours worked / day, demonstrating that the daily working hours, when more than 8 hours, contributing to the onset of musculoskeletal disorders, interfering in performing normal daily activities such as housework, work and leisure. So the professionals who work long continuous hours in uncomfortable positions, with a high volume of calls, without holding breaks may present some kind of pain or discomfort ${ }^{15,16,21}$. The short breaks are as important as the regimented labor stretches or long breaks, since they allow the professional to conduct some postures to reduce muscle tension, without interrupting the pace of work during short breaks, like drinking water, going to the bathroom, or between servicing of patients. These short breaks bring a release of accumulated lactic acid by prolonged postures, improving tissue oxygenation ${ }^{26}$.

Performing rest breaks is not a vital need of the body, but the introduction of this practice in daily life can reduce mental and physical fatigue, especially for workers such as dentists who perform activities that require much of the nervous system, in mental work, where finger dexterity and the requirement of the sense organs is of utmost importance ${ }^{27}$.

The results of this study were a high prevalence of musculoskeletal disorders among dentists and the region of the upper limbs and lower back region were the most affected. The extension of daily working hours proved to be a factor that interferes with pain, disabling the professional to perform their daily activities. The perception of professionals in relation to risk for the onset of painful symptom factors was considered severe in symptomatic individuals. More research on the subject becomes interesting for the purpose of further analysis on the installation, demonstration and prevention of musculoskeletal disorders in dentists, including the identification of risk factors and their impact on labor activity. 


\section{Acknowledgement}

We appreciate the funding from the Fundação de Amparo a Pesquisa de São Paulo (Foundation for Support and Research of São Paulo) (FAPESP).

\section{References}

1. Hayes MJ, Smith DR, Taylor JA. Musculoskeletal Disorders in a 3 Year Longitudinal Cohort of Dental Hygiene Students. J Dent Hyg. 2014 Feb;88(1): 36-41.

2. Graham C. Ergonomics in dentistry, Part 1. Dent Today. 2002 Apr;21(4):98-103.

3. Yarid SD, Diniz DG, Orenha ES, Arcieri RM, Garbin AJI. [Application of ergonomics principles in dental care]. Interbio. 2009;3(2);11-7. Portuguese.

4. Garbin AJI, Garbin CAS, Diniz DG, Yarid SD. Dental students' knowledge of ergonomic postural requirements and their application during clinical care. Eur J Dent Educ. 2011 Feb;15(1):31-5. doi: 10.1111/j.16000579.2010.00629.x.

5. Yi J, Hu X, Yan B, Zheng W, Li Y, Zhao Z. High and specialty-related musculoskeletal disorders afflict dental professionals even since early training years. J Appl Oral Sci. 2013 Jul-Aug;21(4):376-82. doi: 10.1590/1678-775720130165.

6. Durgha K, Sakthi DR. Occupational hazards and its impact on quality of life of dentists. IOSR J Dent Med Sci. 2014;13(7):53-6.

7. Babaji P, Samadi F, Jaiswal JN, Bansal A. Occupational hazards among dentists: A review of literature. J Int Dent Med Res. 2011;4(2):87-93.

8. Hayes MJ, Cockrell D, Smith DR. A systematic review of musculoskeletal disorders among dental professionals. 2009 Aug;7(3):159-65. doi: 10.1111/j.1601-5037.2009.00395.x.

9. Hayes MJ, Smith DR, Taylor JA. Musculoskeletal disorders and symptom severity among Australian dental hygienists. BMC Res Notes. $2013 \mathrm{Ju}$ 4:6:250. doi: 10.1186/1756-0500-6-250.

10. Hayes MJ, Smith DR, Taylor JA. Predictors of MSD among dental hygienists. Int J Dent Hyg. 2012 Nov;10(4):265-9. doi: 10.1111/j.16015037.2011.00536.x

11. Kotliarenko A, Michel-Crosato E, Biazevic MG, Crosato E, Silva PR. [Osteomuscular disorders and related factors in dental surgeons from the Central West region of Santa Catarina state]. Rev Odonto Cienc. 2009;24(2):173-9. Portuguese.

12. Barros ENC, Alexandre NMC. Cross-cultural adaptation of the Nordic musculoskeletal questionnaire. IntNurs Rev. 2003 Jun;50(2):101-8.

13. Coluci MZO, Alexandre NMC. Cross-cultural adaptation of an instrument to measure work-related activities that may contribute to osteomuscular symptoms. Acta Paul Enferm. 2009;22(2):149-54.
14. ChismarkA, Asher G, Stein M, Tavoc T, Curran A. Use os complementary and alternative medicine for Work-Related pain correlates with career satisfaction among dental hygienists. J Dent Hyg. 2011 Fall;85(4):273-84.

15. Barros SS, Ângelo RCO, Uchôa EPBL. Occupacional low back pain and sitting position. Rev Dor Sao Paulo. 2011 Oct-Dec;12(4):308-13.

16. Aljanakh M, Shaikh S, Siddiqui AA, Al-Mansour M, Hassan SS. Prevalence of musculoskeletal disorders among dentists in the Ha'il Region of Saudi Arabia. Ann Saudi Med. 2015 Nov-Dec;35(6):456-61. doi: 10.5144/0256-4947.2015.456

17. Prudhvi K, Murthy KR. Self-reported musculoskeletal pain among dentists in Visakhapatnam: a 12-month prevalence study. Indian J Dent Res. 2016 Jul-Aug;27(4):348-352. doi: 10.4103/0970-9290.191880.

18. Reis P, Moro AR, Da Silva J, Paschoarelli L, Nunes Sobrinho F, Peres L. Anthropometric aspects of body seated in school. Work. 2012;41 Suppl 1:907-14

19. Batham C, Yasobant S. A risk assessment study on work-related musculoskeletal disorders among dentists in Bhopal, India. Indian J Dent Res. 2016 May-Jun;27(3):236-41. doi: 10.4103/0970-9290.186243.

20. Medeiros UV, Segatto GG. [Injuries for repetitive strain (RSI) and work related musculoskeletal disorders (WRMD) in dentists]. Rev Bras Odontol. 2012 Jan-Jun;69(1):49-54. Portuguese.

21. Souza IMA, Vasconcelos TB, Bastos VPD, Farias MSQ. [Evaluation of pain and injuries caused by work in dentists in Fortaleza / CE]. Rev Fisioter S Fun. 2012 Jul-Dec;1(2):35-41. Portuguese.

22. Silva HPL, Jesus CS. [Musculoskeletal symptoms among dentists of the public service]. Rev AMRIGS. 2013 Jan-Mar;57(1):44-8. Portuguese.

23. Biswas R, Sachdev V, Jindal V, Ralhan S. Musculoskeletal disorders and ergonomic risk factors in dental pratice. Ind J Dent Sci. 2012 Mar;4(1):70-4.

24. Alexandre PCB, Silva ICM, Souza LMG, Magalhães Câmara V, Palácios M, Meyer A. Musculoskeletal disorders among brazilian dentists. Arch Env Occup Health. 2011;66(4):231-5. doi: 10.1080/19338244.2011.564571.

25. Wang SY, Liu LC, Lu MC, Koo M. Comparisons of musculoskeletal disorders among ten different medical professions in Taiwan: a nationwide, population-based study. PLoS One. 2015 Apr 10;10(4):e0123750. doi: 10.1371/journal.pone.0123750.

26. Alexopoulos E, Stathi IC, Charizani F. Prevalence of musculoskeletal disorders in dentists. BMC Musculosk Disord. 2004 Jun;5:16. 8p. Doi: 10.1186/1471-2474-5-16

27. Regis Filho GI, Michels G, Sell I. [Work related musculoskeletal disorders in dentists]. Rev Bras Epidemiol. 2006;9(3):346-59. Portuguese. 